F. med. Genet. (1968). 5, 319.

\title{
Congenital Microcephaly with Hiatus Hernia and Nephrotic Syndrome in Two Sibs
}

\author{
W. H. GALLOWAY and A. P. MOWAT \\ From the Department of Child Health, University of Aberdeen
}

The familial occurrence of idiopathic nephrotic syndrome, hiatus hernia, or microcephaly is recognized. No previous report has been found of all three conditions occurring in members of a sibship, and the following case reports may therefore be of interest.

\section{Case Reports}

The parents are healthy. They have no evident features of the above conditions, nor are they aware of their occurrence in any members of their families. There is no consanguinity in the last four generations.

Case 1. Their first child, a boy, was born on October 1956, the father then being 23 years old, the mother 21 years old. Pregnancy and delivery were uncomplicated though the mother had had an $x$-ray of the pelvis for suspected disproportion in late pregnancy. At birth the child weighed $3015 \mathrm{~g}$. $(6 \mathrm{lb} .10 \mathrm{oz}$.) and showed no features of prematurity, in spite of a stated gestation of 34 weeks. Conception antedated marriage. The placenta weighed $630 \mathrm{~g}$. (1 lb. $6 \mathrm{oz}$.).

In the first week of life, the infant developed diarrhoea with pyuria and proteinuria. Sulphadimidine was prescribed for one week and these features settled. Frequent vomiting occurred from the second week of life. At 3 months of age a large hiatus hernia was shown radiologically. The head circumference at that time was $35 \mathrm{~cm}$. He was admitted to hospital at 9 months because of refusal to feed. The child had shown little interest in his surroundings, had little head control, and could not sit up.

The main abnormal findings then were microcephaly (head circumference $38 \mathrm{~cm}$.) and poor motor development, with generalized hypotonia and no purposeful movements. The skull was peculiarly shaped, the forehead was receding, and from prominent ridges above the ears the lateral aspects sloped towards a flat vertex. Radiological examination showed a degree of platybasia. There was pitting dependent oedema and massive proteinuria. The serum cholesterol was $220 \mathrm{mg}$., the serum proteins showing diminished albumin and $\gamma$-globulin with raised $\alpha_{2}$-globulins. There was no

Received January 29, 1968. evidence of possible aetiological factors for the nephrotic syndrome, such as mercury ingestion, thrombosis of the inferior vena cava or renal veins, or luetic infection. No sucrosuria was found. The child's condition deteriorated rapidly, and he died 19 days after admission, in spite of a high protein, low salt regimen.

At necropsy, oedema, ascites, and bilateral hydrothorax were found. There was incipient bronchopneumonia. The oesophagus was considered normal, there being no demonstrable hiatus hernia. Both kidneys weighed $45 \mathrm{~g}$. (average $30-35 \mathrm{~g}$.). There was notable pallor of the renal cortex. Microscopy showed no conspicuous abnormality of the glomeruli, but a few did show proliferation of Bowman's capsule, increased cellularity, and infrequent adhesions. There was widespread hyaline droplet change in the proximal tubules. The brain weighed only $360 \mathrm{~g}$. The sulci were wide on macroscopical examination. Histological examination was not carried out.

A second male child, born in 1958, is well, with no features of these conditions.

Case 2. The third child of the marriage, a girl, was born in September 1964, after a normal pregnancy lasting 39 weeks. The delivery and neonatal period were unremarkable.

Her birthweight was 2730 g. (6 lb.). She was first seen in the out-patient department when 13 months, because of slow mental development. The child was uninterested in her surroundings, had little head control, and made no use of her hands. The head circumference was $39 \mathrm{~cm}$. The skull was abnormally shaped, the forehead was narrow and receding, the occiput was flat, and the lateral aspects sloped towards a somewhat pointed vertex. Skull radiographs were normal. The child had vomited repeatedly since birth.

At the age of 2 years, periorbital and dependent oedema developed two weeks after an upper respiratory tract infection. On admission to hospital, the abnormal findings were marked generalized oedema, skin and mucosal pallor, and massive proteinuria. Her mental state and motor development were unchanged, as was her head circumference. Intermittent episodes of neck retraction occurred.

The total serum proteins were $4.2 \mathrm{~g}$., and on electrophoresis consisted of albumin, $44 \% ; \alpha_{1}$-globulin, $6 \%$; 319 $\alpha_{2}$-globulin, $24 \% ; \beta$-globulin, $11 \%$; and $\gamma$-globulin, 
$15 \%$. There was a severe hypochromic microcytic anaemia, the haemoglobin being $5.6 \mathrm{~g} . / 100 \mathrm{ml}$. The serum iron was. $20 \mu \mathrm{g} . / 100 \mathrm{ml}$.

The stools persistently contained occult blood. Radiological examination showed a well-marked hiatus hernia with free gastro-oesophageal regurgitation. $X$-ray of the cervical spine showed calcification of the intervertebral disc between cervical vertebrae 5 and 6 . The spine was otherwise normal radiologically. No intracranial calcification was seen.

Normal investigations included culture of throat swab and urine and urine microscopy. The anti-streptolysin O level was not raised. Blood urea was normal, as were the urinary amino acids. No sucrosuria was found. The karyotype was normal.

With oral prednisolone the features of the nephrotic syndrome gradually improved over four weeks, but the urine continued to contain a trace of protein. Occult alimentary bleeding persisted in spite of nursing in a 'hiatus hernia' box and giving antacids by mouth. The anaemia which had persisted unchanged in spite of normal doses of oral iron was corrected by the transfusion of $200 \mathrm{ml}$. whole blood. This had no apparent effect on the nephrotic syndrome. She was discharged from hospital on $20 \mathrm{mg}$. prednisolone per day, but had to be readmitted four weeks later because of severe anaemia which again was treated by blood transfusion. The urine during this admission contained pus cells, and culture produced a growth of Esch. coli for which nitrofurantoin was prescribed.

During the ensuing four months, there was no essential change other than the development of Cushingoid side-effects. The steroid dosage was reduced to $20 \mathrm{mg}$. on alternate days without apparent deterioration of her nephrotic state. She was finally admitted with increased vomiting and bloody diarrhoea. Rapid deterioration occurred, with death four days after admission. Salmonella typhimurium was recovered from the stools.

At necropsy, the legs were noted to be oedematous and the face Cushingoid. Early bronchopneumonic consolidation was present at the lung bases.

The brain weighed $400 \mathrm{~g}$. (average normal $600 \mathrm{~g}$.). Extensive ante-mortem thrombus was found occluding the sagittal, straight, transverse, and sigmoid sinuses. Congestion of the surface extended $1 \mathrm{~cm}$. into the cortex. There was an area of cerebral softening in the right parietal lobe, where the surface vessels showed thrombosis. No other pathological features were found.

The kidneys (left 48 g., right 55 g.) were easily stripped of their capsules. Pallor was evident but the architecture of the pyramids was normal.

Histologically, the glomeruli showed no abnormality other than in the cortico-medullary area in which focal membranous thickening in the glomerular tufts and areas of inter- and intra-capillary fibrinoid deposition was found. There was no evidence of proliferative glomerulonephritis. The tubules showed areas of dilatation, being filled with proteinaceous material, with marked hyaline droplet change in the proximal tubules.

The oesophagus was macroscopically normal, no hiatus hernia being demonstrated.

\section{Discussion}

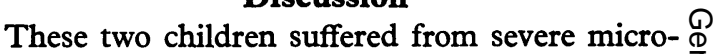
cephaly, a significant hiatus hernia, and nephrotic $\stackrel{\oplus}{\oplus}$ syndrome, which in the first child ran a rapidly

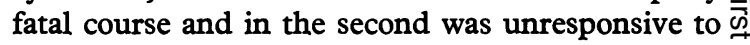
steroids.

Understanding of the role of genetic or en- $\frac{\bar{\sigma}}{\sigma}$ vironmental factors in the pathogenesis of familial $\frac{\bar{m}}{\frac{D}{5}}$ nephrosis is hampered by the lack of clear clinical $\stackrel{\varnothing}{\propto}$ or pathological features by which congenital, infan- \& tile, or familial nephrosis and idiopathic nephrotic $\vec{\circ}$ syndrome may be distinguished. In the literature there appears to be no clear separation of these $\vec{\omega}$ varieties of nephrosis by their apparent time of on- $\Omega$ set. Congenital nephrosis, as defined by Norio (1966), starts within the first few weeks of life. in McCrory, Shibuya, and Worthen (1966), in a recent $\rightarrow$ review of familial nephrosis, considered that nephro- $\stackrel{\omega}{\omega}$ sis identical with congenital nephrotic syndrome 6 could occur as late as 10 months of age. More commonly nephroses present at birth or appearing in the neonatal period are considered as one group. $\mathbb{D}$ This has enabled Hallman and Hjelt (1959) to dis- $\mathbb{D}$ tinguish some commonly associated features. 긍 Typically the child is born three weeks before term, the birthweight is low, and the placenta is large, be- $\vec{\varphi}$ ing up to one-fourth of the weight of the child $\$$ The nephrosis runs a persistent course, unrespon sive to all treatment, and is invariably fatal. Come monly cystic-like dilatations in the proximal tubules are found.

Consideration of such cases, as those reported by $\frac{\mathrm{O}}{\mathbb{D}}$ Giles et al. (1957), and the intensive pedigree studies of Norio (1966), indicate that nephrosis occurring at this age is probably an inherited disorder, apparently due to a recessive autosomal gene.

Our first case has some features of the infantile nephrotic syndrome, in that it occurred under the age of 10 months, was unresponsive to treatment, and had a fatal outcome. The second child's illness is, however, indistinguishable from the sporadic idiopathic nephrotic syndrome.

Familial nephrosis occurring at a later age commonly runs a consistent course in any one family. Cases have occurred in twins (Goettsch, 1948; Prader, 1950), and examples of two or more affected sibs have been reported (Werner, 1942; Fanconi, Kousmine, and Frischknecht, 1951; N Barnett, Forman, and Lauson, 1952; Vernier, N Brunson, and Good, 1957). The genetics of this familial variant have not been determined.

Efforts to demonstrate consanguinity in the parents of our cases have been unsuccessful, in $\stackrel{?}{?}$ spite of tracing the family tree back to the children's $\square$ great-grandparents. Both children did, however, 
suffer from microcephaly, for which no acquired cause could be shown histologically in the second case. The microcephaly was morphologically similar to that considered by Van den Bosch (1955), who in a study of five families with many cases of microcephaly concluded that the condition was determined by a recessive autosomal gene.

The failure to demonstrate at necropsy any evidence of hiatus hernia is not unexpected in view of the known excellent prognosis of the condition with the management described (Carré, 1959; Roviralta, 1964).

There are few references to the familial occurrence of hiatus hernia. In a report of 58 cases of hiatus hernia in children, Thomsen (1955) found hiatus hernia in two pairs of sibs, one pair being binovular twins, suggesting that a genetic factor may be of some importance in this condition. Interestingly, one other case had microcephaly in addition.

Since nephrosis, microcephaly, and hiatus hernia are conditions which in some circumstances are genetically determined, it is concluded that in the two cases described, these conditions probably had a genetic basis.

\section{Summary}

The clinical history and necropsy findings are described in two sibs who suffered from microcephaly, hiatus hernia, and nephrotic syndrome. No consanguinity of the parents was shown. The possible genetic basis of these conditions is discussed.
We are indebted to Drs. R. T. MacPherson and P. A. Walker, of the Department of Pathology, University of Aberdeen, for the necropsy reports in Cases 1 and 2, respectively. Chromosome analysis in Case 2 was possible due to the kindness of Professor Polani of the Paediatric Research Unit, Guy's Hospital Medical School, London S.E.1.

\section{REFERENCES}

Barnett, H. L., Forman, C. W., and Lauson, H. D. (1952). The nephrotic syndrome in children. Advanc. Pediat., 5, 53.

Carré, I. J. (1959). The natural history of the partial thoracic stomach (hiatus hernia) in children. Arch. Dis. Childh., 34, 344.

Fanconi, G., Kousmine, C., and Frischknecht, W. (1951). Die konstitionelle Bereitschaft zum Nephrosesyndrom. Helv. paediat. Acta, 6, 199.

Giles, H. McC., Pugh, R. C. B., Darmady, E. M., Stranack, F., and Woolf, L. I. (1957). The nephrotic syndrome in early infancy: a report of three cases. Arch. Dis. Childh., 32, 167.

Goettsch, E. (1948). Nephritis and nephrosis. In Brennemann's Practice of Pediatrics, vol. 3. W. F. Prior, Hagerstown, Maryland. Hallman, N., and Hjelt, L. (1959). Congenital nephrotic syndrome. F. Pediat., 55, 152.

McCrory, W. W., Shibuya, M., and Worthen, H. G. (1966). Hereditary renal glomerular disease in infancy and childhood. Advanc. Pediat., 14, 253.

Norio, R. (1966). Heredity in the congenital nephrotic syndrome A genetic study of 57 Finnish families with a review of reported cases. Ann. Paediat. Fenn., 12, Suppl. 27.

Prader, A. (1950). Lipoidnephrose bei einiigen Zwillingen. Helv. paediat. Acta, 5, 392.

Roviralta, E. (1964). The natural evolution of hiatal hernias. Arch. Dis. Childh., 39, 143.

Thomsen, G. (1955). Hiatus Hernia in Children. A RadiologicClinical Study Comprising 58 Cases. Danish Science Press, Copenhagen.

Van den Bosch, J. (1955). Microcephale kinderen uit huwelijken tussen bloedverwanten. Ned. T. Geneesk., 99, 3773.

Vernier, R. L., Brunson, J., and Good, R. A. (1957). Studies on familial nephrosis. 1. Clinical and pathologic study of four cases in a single family. Amer. F. Dis. Child., 83, 469.

Werner, M. (1942). In Handbuch der Erbbiologie des Menschen. Ed. by G. Just. Springer, Berlin. 